\title{
Current status and future prospects of pharmacovigilance in Pakistan
}

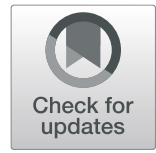

\author{
Rabia Hussain * (10) and Mohamed Azmi Hassali
}

\begin{abstract}
Countries all around the globe are working to establish robust pharmacovigilance systems. Whereas the majority of the developed countries have established well-organized pharmacovigilance systems, the developing countries still lack the basic infrastructure to establish such systems. This commentary focuses on the need of pharmacovigilance and its current status and future trends in Pakistan.
\end{abstract}

Keywords: Pakistan, Pharmacovigilance, Adverse drug reaction, DRAP

\section{Background}

There is always a tradeoff between medicines' side effects and the therapeutic benefits. However, evidences suggest that adverse drug reaction are very common, and may lead to hospitalization and even death [1]. To avoid adverse drug related hospitalization and mortality, an evaluation mechanism to ensure safety and monitoring of the medicines is needed [2]. The evaluation mechanism is known as pharmacovigilance, which involves detection, assessment, understanding and prevention of adverse drug effects [3]. The aim of pharmacovigilance is to identify a possible harm, which is then analyzed and investigated to minimize the hazard. This information is further communicated to the healthcare professionals and general public to improve the healthcare and patient safety [4].

\section{Why pharmacovigilance is important?}

Medicines, during clinical trials are evaluated for their safety profile on carefully selected individuals only. However, after their release in the market, medicines are monitored during post marketing surveillance phase which relies on spontaneous reporting of adverse drug reaction (ADR) [2]. The World Health Organization (WHO) defines an ADR as any drug effect, which is noxious, unintended and undesired effect and occur at normal therapeutic doses [5]. It happens due to number of reasons, such as the limitation of scope of clinical trial

\footnotetext{
* Correspondence: rabia.hussain2010@gmail.com

School of Pharmaceutical Sciences, Universiti Sains Malaysia, 11800 Penang, Malaysia
}

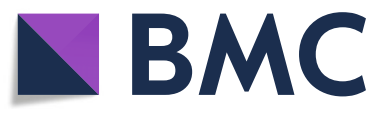

(C) The Author(s). 2019 Open Access This article is distributed under the terms of the Creative Commons Attribution 4.0 International License (http://creativecommons.org/licenses/by/4.0/), which permits unrestricted use, distribution, and

reproduction in any medium, provided you give appropriate credit to the original author(s) and the source, provide a link to the Creative Commons license, and indicate if changes were made. The Creative Commons Public Domain Dedication waiver (http://creativecommons.org/publicdomain/zero/1.0/) applies to the data made available in this article, unless otherwise stated. data to a specific population sample, patients may experiencing co-morbidities or using other drugs, off-label use of drugs or variation in the genetic makeup of individuals [6].

Due to Thalidomide disaster in early 60 s, thousands of babies were born with no or malformed limbs [7, 8]. Following this incident, in 1971, the WHO, established a program for international drug monitoring for early detection of ADRs with other member countries [9]. WHO also recommended every country to establish a national pharmacovigilance center to identify medicines which are more prone to exhibit ADRs. As a result, now member countries send report for such drugs to Uppsala Monitoring Centre (UMC), which further investigates and disseminates the necessary information globally. Currently, 134 member countries are working with UMC in Sweden including both developed and developing countries. [3]. However, $96 \%$ of the developed countries have national pharmacovigilance systems in collaboration with UMC, while only $27 \%$ of the Low and Middle Income Countries (LMICs) have such established pharmacovigilance systems. This lower number of pharmacovigilance systems in LMICs is due to lack of resources and infrastructure [10].

\section{Pharmacovigilance in Pakistan}

Pakistan ranks 6th among the most populous country and has a population of about 207.8 million [11, 12]. In 2003, it was mentioned in the National Drug Policy of Pakistan to establish a drug monitoring and surveillance system [13]. However, the work on 
pharmacovigilance did not started until 2012, when an adverse drug reaction (ADR) due to a locally produced drug Isotab $20 \mathrm{mg}$ (Isosorbide mononitrate, batch number J093) resulted in the deaths of more than 200 patients in Lahore [14].

Following the incident, the Supreme Court of Pakistan ordered the government to establish an independent drug regulatory authority (WHO, 2018). Thereafter, under Drug Regulatory Authority of Pakistan (DRAP) Act in 2012, DRAP was established. The DRAP serves as one of the six ministerial divisions of National Health Services Regulation and Coordination (NHSRC) to regulate the safety, quality and availability of medical devices and medicines in the country [13]. The DRAP devised a framework for post marketing surveillance of drugs with the collaboration of the United States Pharmacopoeia and Promoting Quality Medicines (USP-PQM). Drug Regulatory Authority of Pakistan (DRAP) also established a National Pharmacovigilance Centre in 2017 as well as other regional pharmacovigilance centres in the country in 2018 [15, 16]. As a result of these efforts, in 2018, Pakistan became the full member of UMC [16].

DRAP has formulated guidelines for pharmacovigilance activities and its provincial drug control unit is regularly publishing drug safety alerts based on the evidence provided through the post marketing surveillance [17]. In 2018, DRAP has organized a special training named as, "Training of Trainers, Pharmacovigilance Development of Pakistan" for the DRAP officers and focal persons from tertiary care hospitals. Furthermore, basic trainings and lectures have also been planned by DRAP to educate and train healthcare professionals about pharmacovigilance [18].

To strengthen spontaneous reporting of an ADR, the DRAP has launched an online reporting form named as "Med Vigilance" on DRAP's official website, which is available for patients, pharmaceutical companies and healthcare professionals to report any adverse drug reaction and adverse events (DRAP, 2018). By doing so, the National Pharmacovigilance Centre (NPC) is not only fulfilling WHO's aim of improving patient care and safety from medicine's use perspective but also contributing towards the assessment of benefits, risks and costeffective use of medicines [2].

\section{Future of pharmacovigilance in Pakistan}

To promote safe use of medicines, good pharmacovigilance practices must be established to ensure the rational use of data for right purpose, however, challenges exist in the form of logistical, financial and legal constraints [19]. Pakistan needs multi-stakeholders' efforts and the standardized methods to assess severity, cause and preventability of possible ADRs. To date, there is no such data available to WHO centre for drug monitoring
(UMC) about ADRs' statistics from Pakistan, in this context, these efforts would also help the collection of this data [14]. There is also a dire need to improve communication between Pakistan Pharmacovigilance Centre and healthcare professionals, which can be done by employing various strategies such as letters to doctors, medicine alerts, newsletters, media statements, patient information leaflets and personal feedback to the ADR reporter [2]. Besides, the healthcare professions must be trained to take the lead and prioritize medication safety reporting in healthcare system involving key areas of reporting like how, when, where and what to include, while documenting an ADR. [14, 19]. With each passing day, new medicines are coming into the market, thus, stakeholders need to pay attention to pharmacovigilance in public health programmes and in the regulation of medicines to improve healthcare delivery [2].

\section{Conclusion}

Medication safety has emerged as a great challenge to all the nations worldwide and many developed countries have pharmacovigilance systems in place to tackle this problem. The pharmacovigilance system of Pakistan is still at its infancy, and many reforms have been introduced by the government body to improve the system. However, the pharmacovigilance system requires a major revamp, which includes a multi-stakeholders' approach and standardization of methods to address medicines safety issues in the country.

\section{Abbreviations}

ADR: Adverse drug reaction; DRAP: Drug Regulatory Authority of Pakistan; UMC: Uppsala Monitoring Centre; WHO: World Health Organization

\section{Acknowledgements}

None to declare.

Funding

Not applicable.

Availability of data and materials

Not applicable.

Authors' contributions

Conceived the idea: $\mathrm{RH} \& \mathrm{AH}$, Wrote the manuscript: $\mathrm{RH}$, finalized and approved the manuscript: $\mathrm{RH} \& \mathrm{AH}$.

Ethics approval

Not applicable.

Consent for publication

Not applicable.

Competing interests

The authors declare that they have no competing interests.

\section{Publisher's Note}

Springer Nature remains neutral with regard to jurisdictional claims in published maps and institutional affiliations. 
Received: 15 April 2019 Accepted: 25 April 2019

Published online: 21 May 2019

\section{References}

1. WHO. Reporting and Learning systems for medication errors: the role of pharmacovigilance centres. World Health organization 2014. https://apps. who.int/iris/bitstream/handle/10665/137036/9789241507943_eng. pdf? sequence=1. Accessed 1st April 2019.

2. WHO. WHO policy perspectives on medicines Pharmacovigilance: ensuring the safe use of medicines. World health organization. 2004. Accessed 31st March 2019.

3. WHO. Pharmacovigilance. World Health Organization. 2004. https://www. who.int/medicines/areas/quality_safety/safety_efficacy/pharmvigi/en/. Accessed 31st March 2019.

4. Waller P, Harrison-Woolrych M. An introduction to pharmacovigilance: John Wiley \& Sons; 2017.

5. WHO. Safety of medicines - a guide to detecting and Reporting Adverse Drug reaction. World Health Organization. 1972. http://apps.who.int/ medicinedocs/en/d/Jh2992e/2.html. Accessed 31st March 2019.

6. Moore N, Bégaud B. Improving pharmacovigilance in Europe. British Medical Journal Publishing Group. 2010.

7. Kim JH, Scialli AR. Thalidomide: the tragedy of birth defects and the effective treatment of disease. Toxicol Sci. 2011;122(1):1-6.

8. Vargesson N. Thalidomide-induced teratogenesis: history and mechanisms Birth Defects Research Part C: Embryo Today: Reviews. 2015;105(2):140-56.

9. WHO. Adverse Drug Reactions Monitoring. World Health Organization. https://www.who.int/medicines/areas/quality_safety/safety_efficacy/ advdrugreactions/en/. Accessed March 30th 2019.

10. Pirmohamed M, Atuah KN, Dodoo AN, Winstanley P. Pharmacovigilance in developing countries. British Medical Journal Publishing Group. 2007.

11. Rana S. 6th census findings: 207 million and counting. The Express Tribune. 2017. https://tribune.com.pk/story/1490674/57-increase-pakistanspopulation-19-years-shows-new-census/. Accessed 31st March 2019

12. Nivya K, Kiran VSS, Ragoo N, Jayaprakash B, Sekhar MS. Systemic review on drug related hospital admissions-a pubmed based search. Saudi Pharmaceutical Journal. 2015;23(1):1-8.

13. Atif M, Ahmad M, Saleem Q, Curley L, Zaman M, Babar Z. Pharmaceutical policy in Pakistan. In: Babar Z, editor. Pharmaceutical policy in countries with developing healthcare systems. Springer International; 2017. p. 25-44.

14. Hussain R, Hassali MA, Hashmi F, Farooqui M. A qualitative exploration of knowledge, attitudes and practices of hospital pharmacists towards adverse drug reaction reporting system in Lahore. Pakistan Journal of pharmaceutical policy and practice. 2018;11(1):16.

15. TET. DRAP plans pharmacovigilance centre in country. The Express Tribune, Punajb. 2018. https://tribune.com.pk/story/1708070/1-drap-planspharmacovigilance-centre-country/. Accessed 30th March 2019.

16. UMC. Global Pharmacovigilance. World Health Organization, Sweden. 2018 https://www.who-umc.org/global-pharmacovigilance/members/. Accessed 30th March 2019.

17. PDCU. Drug Safety Alerts. Provincial Drug control unit, Punjab. 2018. https:// sites.google.com/prod/view/pdcup/divisions/drug-safety-alerts. Accessed 31st March 2019

18. DAWN. US team to provide training on monitoring side effects of drugs Dawn News, Islamabad. 2018. https://www.dawn.com/news/1406218. Accessed 4th April 2019

19. Meyboom RH, Egberts AC, Gribnau FW, Hekster YA. Pharmacovigilance in perspective. Drug Saf. 1999;21(6):429-47.

Ready to submit your research? Choose BMC and benefit from:

- fast, convenient online submission

- thorough peer review by experienced researchers in your field

- rapid publication on acceptance

- support for research data, including large and complex data types

- gold Open Access which fosters wider collaboration and increased citations

- maximum visibility for your research: over $100 \mathrm{M}$ website views per year

At BMC, research is always in progress.

Learn more biomedcentral.com/submissions 